\title{
Inhaled epoprostenol (prostacyclin) and pulmonary hypertension before cardiac surgery
}

\author{
Manon Haché, MD, André Denault, MD, FRCPC, Sylvain Bélisle, MD, FRCPC, Danielle Robitaille, MD, FRCPC, \\ Pierre Couture, MD, FRCPC, Peter Sheridan MD, FRCPC, Michel Pellerin, MD, FRCSC, Denis Babin, MSc, \\ Nicolas Noël, BPharm, MSc, Marie-Claude Guertin, MSc, PhD, Raymond Martineau, MD, FRCPC, and \\ Jocelyn Dupuis, MD, FRCPC
}

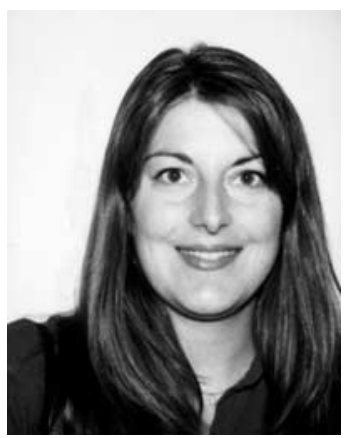

Dr Haché

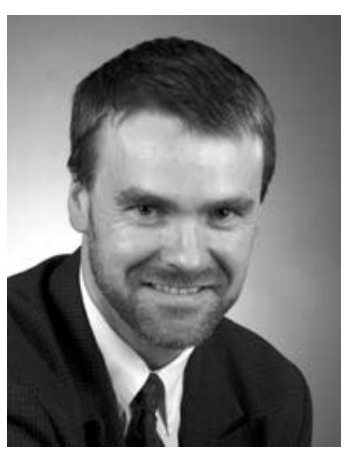

Dr Denault
Objective: Pulmonary hypertension is commonly found in patients undergoing valvular surgery and can be worsened by cardiopulmonary bypass. Inhaled epoprostenol (prostacyclin) has been used for the treatment of pulmonary hypertension, but its effects compared with those of placebo on hemodynamics, oxygenation, echocardiographic examination, and platelet function have not been studied during cardiac surgery.

Methods: Twenty patients with pulmonary hypertension undergoing cardiac surgery were randomized in a double-blind study to receive inhaled epoprostenol $(60 \mu \mathrm{g})$ or placebo. The inhalation occurred after induction of anesthesia and before surgical incision. The effects on left and right systolic and diastolic cardiac functions evaluated by means of pulmonary artery catheterization and transesophageal echocardiography, as well as oxygenation and platelet aggregation, were studied.

Results: Inhalation of epoprostenol significantly reduced indexed right ventricular stroke work from $10.7 \pm 4.57 \mathrm{~g} \cdot \mathrm{m} \cdot \mathrm{m}^{-2}$ to $7.8 \pm 3.94 \mathrm{~g} \cdot \mathrm{m} \cdot \mathrm{m}^{-2}(P=.003)$ and systolic pulmonary artery pressure from $48.4 \pm 18 \mathrm{~mm} \mathrm{Hg}$ to $38.9 \pm 11.9 \mathrm{~mm} \mathrm{Hg}$ $(P=.002)$. The effect was correlated with the severity of pulmonary hypertension $(r=0.76, P=.01)$ and was no longer apparent after 25 minutes. There was no significant effect on systemic arterial pressures, left ventricular function, arterial oxygenation, platelet aggregation, and surgical blood loss.

Conclusion: Inhaled epoprostenol reduces pulmonary pressure and improves right ventricular stroke work in patients with pulmonary hypertension undergoing cardiac surgery. A dose of $60 \mu \mathrm{g}$ is hemodynamically safe, and its effect is completely reversed after 25 minutes. We did not observe any evidence of platelet dysfunction or an increase in surgical bleeding after administration of inhaled epoprostenol.

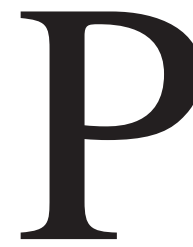

ulmonary hypertension $(\mathrm{PH})$ is associated with an increase in morbidity and mortality in patients undergoing cardiac surgery. ${ }^{1}$ Many drugs have been used in recent years to treat $\mathrm{PH}$. Among these are vasodilators, including epoprostenol (prostacyclin; $\mathrm{PGI}_{2}$ ). However, its intravenous administration is limited by systemic hypotension because of nonselective vasodilation and by hypoxemia through worsening of intrapulmonary shunt caused by inhibition of hypoxic pulmonary vasoconstriction..$^{2,3}$

Inhaled $\mathrm{PGI}_{2}$ appears to be a selective pulmonary vasodilator comparable with inhaled nitric oxide (iNO) but acting through cyclic adenosine monophosphate instead of cyclic guanosine monophosphate. ${ }^{4,5}$ Its administration can be a simpler and less expensive alternative to iNO. Its half-life is 2 to 3 minutes, and at physiologic $\mathrm{pH}$, it spontaneously hydrolyses to 6-ketoprostaglandin $\mathrm{F}_{1 \alpha}$ (6-keto$\mathrm{PGF}_{1 \alpha}$ ). Thus its effect remains localized to ventilated lung units, it can decrease pulmonary artery pressure (PAP) without causing systemic hypotension and im- 
prove oxygenation by decreasing ventilation-perfusion mismatch. $^{5-8}$ Its effect on cardiac function when given by means of inhalation is controversial but it can increase cardiac output when given intravenously. 9,10

Finally, a drawback of $\mathrm{PGI}_{2}$ is that it has been reported to alter platelet function, ${ }^{11}$ which could be hazardous during cardiac surgery.

We have previously reported our retrospective experience with the use of inhaled $\mathrm{PGI}_{2} \cdot{ }^{12}$ However, so far no study has evaluated its effects in patients undergoing cardiac surgery and simultaneously on several important clinical variables, such as the magnitude of its hemodynamic effect and its consequences on echocardiographic indices of right ventricular (RV) and left ventricular (LV) systolic and diastolic functions, oxygenation, platelet function, and bleeding.

\section{Methods}

\section{Population}

After approval by the research and ethics committee and obtaining informed consent, 20 patients with $\mathrm{PH}$ undergoing cardiac surgery with cardiopulmonary bypass were included in the study. Patients were considered to have $\mathrm{PH}$ if systolic pulmonary artery pressure (sPAP) was greater than $30 \mathrm{~mm} \mathrm{Hg}$ or mean pulmonary artery pressure was greater than $25 \mathrm{~mm} \mathrm{Hg}$, as measured during the preoperative period or estimated by using Doppler echocardiography. ${ }^{13}$ This was confirmed after insertion of a pulmonary artery catheter and before induction of general anesthesia. Patients with LV dysfunction (ejection fraction of $<30 \%$ ) or known bleeding diathesis were excluded. Further exclusion criteria were contraindications to transesophageal echocardiography (TEE), including esophageal disease or unstable cervical spine. A Parsonnet score was calculated for every patient. ${ }^{1}$

\section{Protocol}

Patients were premedicated with 1 to $2 \mathrm{mg}$ of lorazepam administered orally 1 hour before the operation, as well as $0.1 \mathrm{mg} / \mathrm{kg}$ morphine administered intramuscularly and 0.2 to $0.4 \mathrm{mg}$ of scopolamine administered intramuscularly before being taken to the operating room. In the operating room additional midazolam was added (0.01-0.05 mg/kg administered intravenously) as needed for patient comfort. Usual monitoring was installed, including a 5-lead electrocardiogram, pulse oximeter, peripheral venous line, radial arterial line, 15-cm 3-lumen catheter (CS-12703, Arrow International Inc, Reading, Calif), and fast-response thermodilution pulmonary artery catheter (Swan-Ganz catheter 7.5F; Baxter Healthcare Corporation, Irvine, Calif). Anesthesia was induced with 0.04 $\mathrm{mg} / \mathrm{kg}$ midazolam and $1 \mu \mathrm{g} / \mathrm{kg}$ sufentanil, and muscle relaxation was achieved with $0.1 \mathrm{mg} / \mathrm{kg}$ pancuronium. After tracheal intubation, anesthesia was maintained with $1 \mu \mathrm{g} \times \mathrm{kg}^{-1} \times \mathrm{h}^{-1}$ sufentanil and $0.04 \mathrm{mg} \times \mathrm{kg}^{-1} \times \mathrm{h}^{-1}$ midazolam. No anesthetic gases were used. Minute ventilation was adjusted to maintain end-tidal carbon dioxide between 30 and $40 \mathrm{~mm} \mathrm{Hg}$ with an infrared carbon dioxide analyzer. A 5.0-MHz TEE omniplane probe (HewlettPackard Sonos 5500, Andover, Mass) was inserted after induction of general anesthesia.

\section{Drug Administration Protocol}

Patients were equally divided into 2 groups to receive either inhaled $\mathrm{PGI}_{2}$ or placebo in a double-blind randomized manner by using a computer-generated randomization table. Epoprostenol (Flolan; Glaxo-Wellcome Inc, Mississauga, Ontario, Canada) was given as epoprostenol $1.5 \mathrm{mg}$ of salt dissolved in sterile glycine buffer diluent, for a concentration of $15 \mu \mathrm{g} / \mathrm{mL}$. Each patient received $4 \mathrm{~mL}$ of a solution containing either $\mathrm{PGI}_{2}$ or normal saline solution (placebo).

The study drug was administered through a jet nebulizer (Ref 8901; Salter Labs, Arvin, Calif) attached to the inspiratory limb of the ventilator near the endotracheal tube. Nebulization was achieved with a bypass flow of oxygen at $8 \mathrm{~L} / \mathrm{min}$. This high flow was used to achieve a high proportion of small particles $(<5 \mu \mathrm{m})$. Because this added a secondary flow to the patient, minute ventilation was adjusted to maintain peak inspiratory pressures of less than $30 \mathrm{~cm} \mathrm{H}_{2} \mathrm{O}$ and a normal end-tidal carbon dioxide.

\section{Measurements}

Hemodynamic parameters included central venous pressure, PAP, and pulmonary artery occlusion pressure. Cardiac output was assessed by using the thermodilution technique with 3 injections of room temperature dextrose $5 \%(10 \mathrm{~mL})$ at end expiration. Systemic vascular resistances, pulmonary vascular resistances, RV stroke work, and LV stroke work were calculated by using a standard formula. Hemodynamic values were indexed for patient body surface area.

Arterial and mixed venous blood gases were obtained to measure $\mathrm{pH}, \mathrm{PO}_{2}, \mathrm{PCO}_{2}, \mathrm{HCO}_{3}{ }^{-}$, and $\mathrm{SO}_{2}$.

TEE examination was performed to evaluate systolic and diastolic parameters of LV and RV performance. The TEE examination included a midesophageal 4-chamber view, a short-axis transgastric view at the midpapillary level, and color flow Doppler imaging of the mitral valve to detect any unsuspected significant mitral valvulopathy. We first obtained a baseline transgastric shortaxis view of the left ventricle at the midpapillary level, followed by a pulsed Doppler examination of pulmonary venous flow, transmitral flow, transtricuspid flow, and hepatic venous flow. The Doppler sample volume (2-mm width) was positioned in the left upper pulmonary vein approximately $1 \mathrm{~cm}$ proximal to its entrance into the left atrium to measure pulmonary venous flow by using color Doppler flow to sample maximal flow. When necessary, to minimize the angle between the Doppler beam and the pulmonary vein's long axis, we rotated the omniplane probe as far as needed from the horizontal plane. This axis was maintained throughout the examination. The same approach was used for hepatic venous flow. Mitral and tricuspid inflow velocities were measured at the tip of the atrioventricular valve leaflets. Three signals were obtained, and the maximal value was computed for analysis. ${ }^{14}$ Two independent observers were involved: the first one recorded hemodynamic parameters, and the other, blinded to the hemodynamic data and to the study drug, simultaneously recorded the pulsed Doppler and 2-dimensional echocardiographic images. All TEE examinations were performed by anesthesiologists who were not in charge of the patient. After data recording, a third anesthesiologist blinded to all data reviewed the recorded sequence. All 2-dimensional images in which the LV and RV endocardial border could not be traced adequately by using Schnittger criteria, in 
TABLE 1. Demographic data of the study population

\begin{tabular}{lrcrcc}
\hline & $\mathbf{n}$ & Epoprostenol & $\mathbf{n}$ & Placebo & $\boldsymbol{P}$ value \\
\hline Age, y & 10 & $65 \pm 11$ & 10 & $58 \pm 12$ & .22 \\
Sex & & & & & \\
$\quad$ Male & 5 & $50 \%$ & 4 & $40 \%$ & 1 \\
$\quad$ Female & 5 & $50 \%$ & 6 & $60 \%$ & \\
Weight, kg & 10 & $76 \pm 17$ & 10 & $70 \pm 20$ & .56 \\
Height, m & 10 & $1.65 \pm 0.11$ & 10 & $1.63 \pm 0.08$ & .65 \\
Parsonnet score & 10 & $29.2 \pm 6.5$ & 10 & $32.4 \pm 10.2$ & .4 \\
Reoperation & 3 & $30 \%$ & 5 & $50 \%$ & .65 \\
Aspirin use & 0 & $0 \%$ & 3 & $30 \%$ & .21 \\
Preoperative heparin & 3 & $30 \%$ & 3 & $30 \%$ & 1 \\
\hline
\end{tabular}

which $80 \%$ of the endocardial contour has to be visualized, were excluded. ${ }^{15}$ In addition, the Doppler signals were reviewed and rejected if they were not laminar and when a clear contour could not be determined for quantification of the velocity-time integral. Severe mitral stenosis or regurgitation were exclusion criteria for the measurement of mitral inflow. All the anesthesiologists performing the TEE measurements were board certified in perioperative TEE. If disagreement occurred between 2 reviewers, a third echocardiographer was asked to review the echocardiographic sequence. Our experience and interobserver variability in the measurement of systolic and diastolic function has been published previously. ${ }^{16,17}$

Platelet aggregation studies were performed on whole blood by using a Chronolog 560 whole blood lumi-aggregometer (Chronolog Corp, Havertown, Pa). Sodium citrate, $0.5 \mathrm{~mL}$ of a $3.2 \%$ solution, was added to $4.5 \mathrm{~mL}$ of venous blood. The citrated blood was diluted 1:1 with normal saline solution. After the solution had been cooled to $20^{\circ} \mathrm{C}$ to $25^{\circ} \mathrm{C}$, a $900-\mu \mathrm{L}$ sample was placed in a cuvette containing a silicone stir bar. After 3 minutes, $100 \mu \mathrm{L}$ of chrono-lume (luciferase luciferon reagent, Chronolog Corp) was added. After another 2 minutes, $2 \mathrm{mmol} / \mathrm{L}$ of adenosine triphosphate (ATP) was added. The ATP standard was then measured for each patient. Two minutes later, an aggregant was added (20 $\mu \mathrm{mol} / \mathrm{L}$ adenosine diphosphate, $5 \mu \mathrm{g} / \mathrm{mL}$ collagen, or $1 \mathrm{nmol} / \mathrm{L}$ arachidonic acid), and platelet aggregation and ATP release (luminescence) were measured. Blood loss was measured for the intraoperative period, as well as for the first 24 hours postoperatively.

Hemodynamic parameters were measured before (T1) and 10 minutes after (T2) induction of anesthesia, after nebulization of $\mathrm{PGI}_{2}$ or placebo (T3), and 15 (T4) and 25 (T5) minutes after nebulization. Arterial and mixed venous blood gases were obtained at the same times, except for T5. TEE examination and platelet aggregation studies were performed before and after administration of $\mathrm{PGI}_{2}$ or placebo. Patients were observed until discharge from the intensive care unit.

\section{Statistical Analysis}

Population size was calculated for a power of $80 \%$ and an $\alpha$ error of .05, assuming an sPAP of $40 \pm 4 \mathrm{~mm} \mathrm{Hg}$ to decrease by $20 \%$ in the $\mathrm{PGI}_{2}$ group and remain stable in the placebo group.

Continuous variables were analyzed with the Student $t$ test and categoric variables with the $\chi^{2}$ or Fisher exact test. Two-factor (time and group) repeated-measures analysis of variance was used to determine time variations between the 2 groups. In case of significant interaction, time $\times$ group comparison was performed with Bonferroni corrections.

The Pearson correlation test was performed to determine the relationship between the level of SPAP and the degree of reduction of sPAP after $\mathrm{PGI}_{2}$ and placebo administration.

\section{Results}

Twenty-seven patients were enrolled in the study. Four were later not randomized because they failed to meet the inclusion criteria for $\mathrm{PH}$ on arrival to the operating room. Two were excluded because the operation was subsequently rescheduled and another because of agitation. Demographic variables were similar in both groups (Table 1).

\section{Hemodynamics}

Baseline hemodynamic variables were similar between the 2 groups (Table 2). Baseline sPAP was $61.2 \pm 19 \mathrm{~mm} \mathrm{Hg}$ in the $\mathrm{PGI}_{2}$ group and $54.3 \pm 14.6 \mathrm{~mm} \mathrm{Hg}$ in the placebo group $(P=.4)$. These decreased significantly after induction of anesthesia in both groups to $48.4 \pm 18 \mathrm{~mm} \mathrm{Hg}$ and $42.7 \pm 12.8 \mathrm{~mm} \mathrm{Hg}$, respectively. After administration of the study drug, a decrease was noted in the $\mathrm{PGI}_{2}$ group to $38.9 \pm 11.9 \mathrm{~mm} \mathrm{Hg}(P=.002)$, as opposed to that seen in the placebo group. Fifteen minutes after the end of nebulization, these values were stable $(42 \pm 12.4$ vs $43.6 \pm 12.5$ $\mathrm{mm} \mathrm{Hg}$ ). After 25 minutes, they returned to baseline in the $\mathrm{PGI}_{2}$ group to $53.3 \pm 17.6 \mathrm{~mm} \mathrm{Hg}$ and remained stable in the placebo group at $43.5 \pm 13 \mathrm{~mm} \mathrm{Hg}$ (Figure 1). There was a significant positive correlation between the severity of $\mathrm{PH}$ before the administration of inhaled $\mathrm{PGI}_{2}$ and the magnitude of the decrease in sPAP $(r=0.76, P=.01)$. Heart rate decreased in the $\mathrm{PGI}_{2}$ group from $64.4 \pm 8.8$ to $58.5 \pm$ 11 beats/min $(P=.002)$. It stayed stable thereafter until 25 minutes after inhaled $\mathrm{PGI}_{2}$, when it increased to $62.8 \pm 11.6$ beats/min $(P=.001)$. Mean PAP did not change significantly after $\mathrm{PGI}_{2}$ administration nor did systemic arterial pressures. Cardiac indexes remained unchanged throughout the study. Compared with placebo, indexed RV stroke work decreased after $\mathrm{PGI}_{2}$ inhalation from $10.7 \pm 4.57$ to $7.8 \pm$ $3.94 \mathrm{~g} \cdot \mathrm{m} \cdot \mathrm{m}^{-2}(P=.003)$ and remained stable thereafter for 25 minutes.

\section{Oxygenation}

Oxygenation data are given in Table 3. The $\mathrm{PaO}_{2}$ value at baseline was significantly different on arrival in the operating room with a nasal cannula at $4 \mathrm{~L} / \mathrm{min}$ of oxygen $\left(173.1 \pm 65.2 \mathrm{~mm} \mathrm{Hg}\right.$ in the $\mathrm{PGI}_{2}$ group vs $251.5 \pm 95.4$ $\mathrm{mm} \mathrm{Hg}$ in the placebo group, $P=.05$ ), but this difference disappeared after induction of anesthesia with a fraction of inspired oxygen of $100 \%(428.2 \pm 65.2$ vs $443.7 \pm 64.9$, respectively; $P=.6$ ). Otherwise, oxygenation variables did not change throughout the study. 
TABLE 2. Hemodynamic variations of the population throughout the study

\begin{tabular}{|c|c|c|c|c|c|}
\hline & T1 & T2 & T3 & T4 & T5 \\
\hline \multicolumn{6}{|l|}{ Epoprostenol } \\
\hline HR (beats/min) & $66.1 \pm 9.7$ & $64.4 \pm 8.8$ & $58.5 \pm 11^{*}$ & $56.7 \pm 10.6$ & $62.8 \pm 11.6 \dagger$ \\
\hline SAP (mm Hg) & $134.4 \pm 28.6$ & $105.3 \pm 15$ & $101.2 \pm 19.3$ & $108.6 \pm 22$ & $124.9 \pm 28$ \\
\hline $\mathrm{MAP}(\mathrm{mm} \mathrm{Hg})$ & $85.9 \pm 14.6$ & $67.9 \pm 11.5$ & $63.8 \pm 10.5$ & $69.7 \pm 13.7$ & $82.6 \pm 19$ \\
\hline CVP $(\mathrm{mm} \mathrm{Hg})$ & $11.1 \pm 6.8$ & $11 \pm 4.9$ & $10.8 \pm 4.8$ & $11.5 \pm 4.9$ & $13.3 \pm 4.3$ \\
\hline PAOP (mm Hg) & $22.8 \pm 8.1$ & $21.8 \pm 6.6$ & $19 \pm 6.4$ & $20.6 \pm 6.6$ & $24.6 \pm 9$ \\
\hline $\mathrm{sPAP}(\mathrm{mm} \mathrm{Hg})$ & $61.2 \pm 19$ & $48.4 \pm 18 \S$ & $38.9 \pm 11.99$ & $42 \pm 12.4$ & $53.3 \pm 17.6 \|$ \\
\hline MPAP $(\mathrm{mm} \mathrm{Hg})$ & $41.5 \pm 9$ & $32.9 \pm 9.2 \S$ & $28.2 \pm 8.2$ & $30.4 \pm 8.4$ & $36 \pm 11.1 \|$ \\
\hline $\mathrm{Cl}\left(\mathrm{L} \cdot \mathrm{min}^{-1} \cdot \mathrm{m}^{-2}\right)$ & $2.5 \pm 0.7$ & $2.2 \pm 0.6$ & $2 \pm 0.5$ & $2 \pm 0.6$ & $1.9 \pm 0.5$ \\
\hline $\mathrm{EV}\left(\mathrm{mL} \cdot\right.$ beat $\left.^{-1} \cdot \mathrm{m}^{-2}\right)$ & $69.4 \pm 20$ & $65.4 \pm 17.3$ & $62.9 \pm 17.6$ & $66 \pm 19.2$ & $56.7 \pm 17.7$ \\
\hline SVRI (dyne $\cdot \mathrm{s} \cdot \mathrm{cm}^{-5}$ ) & $2474 \pm 424.2$ & $2078 \pm 566.6$ & $2260 \pm 381.3$ & $2460 \pm 719.7$ & $3157 \pm 1249$ \\
\hline PVRI (dyne $\cdot \mathrm{s} \cdot \mathrm{cm}^{-5}$ ) & $683.5 \pm 449.1$ & $451.7 \pm 315.6$ & $404.9 \pm 250$ & $398.2 \pm 266.6$ & $555.4 \pm 347.3$ \\
\hline LVSWI $\left(\mathrm{g} \cdot \mathrm{m} \cdot \mathrm{m}^{-2}\right)$ & $33.1 \pm 16.1$ & $21.7 \pm 8.6$ & $22.5 \pm 10.8$ & $24.3 \pm 11.6$ & $24.6 \pm 12.3$ \\
\hline RVSWI $\left(\mathrm{g} \cdot \mathrm{m} \cdot \mathrm{m}^{-2}\right)$ & $15.5 \pm 6.3$ & $10.7 \pm 4.6 \S$ & $7.8 \pm 3.9 \#$ & $8.3 \pm 4.2$ & $8.6 \pm 3.1$ \\
\hline \multicolumn{6}{|l|}{ Placebo } \\
\hline HR (beats/min) & $67.8 \pm 12.5$ & $68.5 \pm 14.4$ & $65.5 \pm 16$ & $61.4 \pm 14.8$ & $61.5 \pm 11.7$ \\
\hline $\mathrm{SAP}(\mathrm{mm} \mathrm{Hg})$ & $142.2 \pm 26.4$ & $118.4 \pm 24.1$ & $119.6 \pm 23.1$ & $117.4 \pm 24.6$ & $119.1 \pm 22.1$ \\
\hline $\mathrm{MAP}(\mathrm{mm} \mathrm{Hg})$ & $92 \pm 14.2$ & $77.3 \pm 13.6$ & $78.4 \pm 14.3$ & $76.7 \pm 16.1$ & $78.6 \pm 11$ \\
\hline CVP $(\mathrm{mm} \mathrm{Hg})$ & $14.4 \pm 7.1$ & $11.3 \pm 5.2 \ddagger$ & $11.7 \pm 4.7$ & $12.6 \pm 4.1$ & $12.9 \pm 4.6$ \\
\hline PAOP $(\mathrm{mm} \mathrm{Hg})$ & $21.7 \pm 11.3$ & $19.7 \pm 8$ & $19.9 \pm 8.4$ & $21.1 \pm 6.5$ & $21.1 \pm 5.8$ \\
\hline sPAP $(\mathrm{mm} \mathrm{Hg})$ & $54.3 \pm 14.6$ & $42.7 \pm 12.8 \ddagger$ & $41.3 \pm 15.2$ & $43.6 \pm 12.5$ & $43.5 \pm 13$ \\
\hline MPAP $(\mathrm{mm} \mathrm{Hg})$ & $38.4 \pm 9.9$ & $30 \pm 9.6 \ddagger$ & $29.6 \pm 13.4$ & $30.4 \pm 9.1$ & $29.6 \pm 7.6$ \\
\hline $\mathrm{Cl}\left(\left(\mathrm{L} \cdot \mathrm{min}^{-1} \cdot \mathrm{m}^{-2}\right)\right.$ & $2.8 \pm 0.8$ & $2.7 \pm 0.8$ & $2.5 \pm 0.7$ & $2.4 \pm 0.7$ & $2.2 \pm 0.6$ \\
\hline $\mathrm{EV}\left(\mathrm{mL} \cdot\right.$ beat $\left.^{-1} \cdot \mathrm{m}^{-2}\right)$ & $73.2 \pm 15.7$ & $67.7 \pm 18.9$ & $68.5 \pm 20.2$ & $68.1 \pm 18.5$ & $63.6 \pm 15.4$ \\
\hline SVRI (dyne $\cdot \mathrm{s} \cdot \mathrm{cm}^{-5}$ ) & $2282 \pm 635.2$ & $2128 \pm 708.3$ & $2290 \pm 776.4$ & $2497 \pm 786.8$ & $2492 \pm 924.3$ \\
\hline PVRI (dyne $\cdot \mathrm{s} \cdot \mathrm{cm}^{-5}$ ) & $521.7 \pm 310$ & $311.8 \pm 147.1$ & $299.5 \pm 161.8$ & $352.9 \pm 208.6$ & $324.5 \pm 276.7$ \\
\hline LVSWI $\left(\mathrm{g} \cdot \mathrm{m} \cdot \mathrm{m}^{-2}\right)$ & $40.4 \pm 18.4$ & $30.3 \pm 11.7$ & $31 \pm 9.6$ & $32 \pm 11.9$ & $27.2 \pm 6.6$ \\
\hline RVSWI $\left(g \cdot m \cdot m^{-2}\right)$ & $13.4 \pm 6.2$ & $9.5 \pm 4.9 \ddagger$ & $8.8 \pm 5$ & $9.5 \pm 5$ & $7.8 \pm 3.9$ \\
\hline
\end{tabular}

$H R$, Heart rate; $S A P$, systemic arterial pressure; $M A P$, mean arterial pressure; $C V P$, central venous pressure; $P A O P$, pulmonary artery occlusion pressure; $M P A P$, mean pulmonary arterial pressure; $C l$, cardiac index; $E V$, ejection volume; SVRI, systemic vascular resistance index; PVRI, pulmonary vascular resistance index; $L V S W I$, LV stroke work index; RVSWI, RV stroke work index.

${ }^{*} P=.002 \mathrm{~T} 2$ to $\mathrm{T} 3$ in prostacyclin group.

$\dagger P=.001 \mathrm{~T} 4$ to $\mathrm{T} 5$ in prostacyclin group.

$\ddagger P<.001 \mathrm{~T} 1$ to $\mathrm{T} 2$ in placebo group.

$\S P<.001 \mathrm{~T} 1$ to $\mathrm{T} 2$ in prostacyclin group.

$\| P<.001$ T3 to T5 in prostacyclin group.

$\Uparrow P=.002 \mathrm{~T} 2$ to $\mathrm{T} 3$ in prostacyclin group.

$\# P=.003 \mathrm{~T} 2$ to $\mathrm{T} 3$ in prostacyclin group.

\section{Echocardiography}

Echocardiography data are given in Table 4. Of 240 images taken, 43 were rejected according to the predefined criteria. There was a $3 \%$ interobserver discordance. TEE examinations were similar in both groups before and after inhalation of $\mathrm{PGI}_{2}$ or placebo, but in the $\mathrm{PGI}_{2}$ group a tendency toward improved fractional area change or systolic function was noted for both the left and right ventricles. Also, in the $\mathrm{PGI}_{2}$ group the systolic portion of hepatic flow tended to increase, and the diastolic portion remained stable compared with that seen with placebo, which suggests improvement in RV diastolic function, but this did not reach statistical significance.

\section{Platelet Aggregation}

Platelet aggregation data are shown in Table 5. Platelet aggregation studies showed a significant difference in plate- let luminescence produced by collagen $(0.8 \pm 0.2 \mathrm{~nm}$ in the $\mathrm{PGI}_{2}$ group vs $1.2 \pm 0.5 \mathrm{~nm}$ in the placebo group, $P=$ .046 ), but this difference remained stable throughout the study ( $0.7 \pm 0.3$ vs $1.1 \pm 0.5 \mathrm{~nm}$, respectively; $P=.055)$.

Otherwise, platelet aggregation studies showed no difference between the 2 groups with either adenosine diphosphate, collagen, or arachidonic acid used as aggregants. Surgical blood loss was similar in both groups for both the intraoperative and postoperative periods.

\section{Discussion}

This is the first randomized controlled trial to examine hemodynamic, echocardiographic, oxygenation, and platelet function effects of inhaled $\mathrm{PGI}_{2}$ versus placebo in patients after anesthesia induction and before cardiac surgery. It confirms that inhaled $\mathrm{PGI}_{2}$ can be a selective pulmonary vasodilator and decrease indexed RV stroke work. Our TEE 


\section{SPAP prostacyclin}

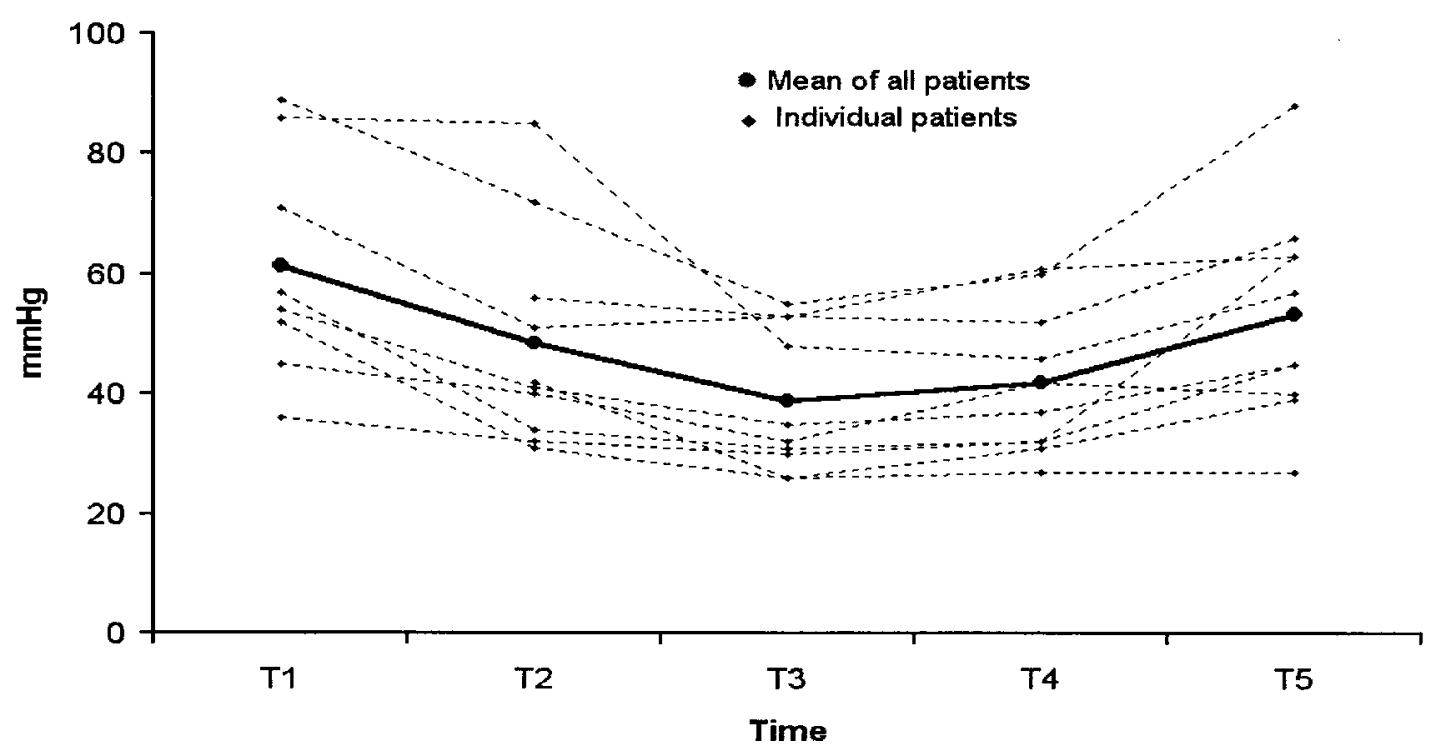

SPAP placebo

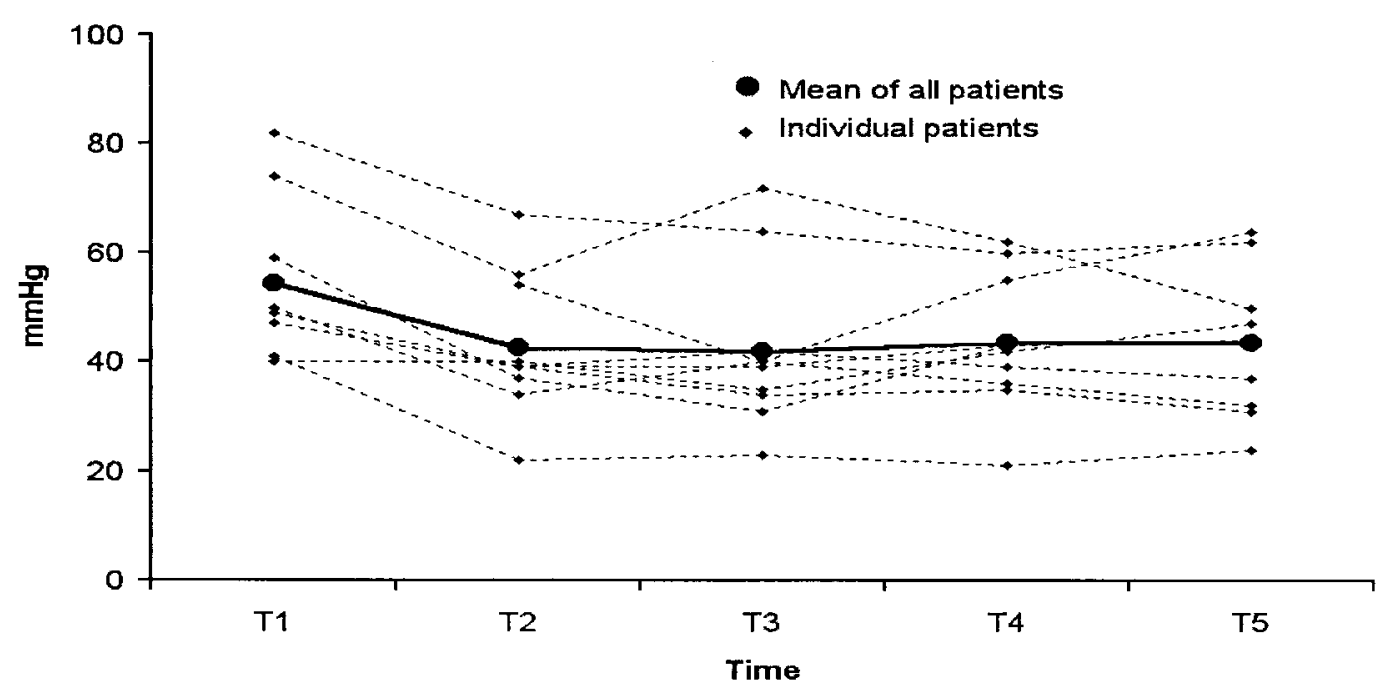

Figure 1. sPAP variations of each patient before (T1) and 10 minutes after (T2) induction of anesthesia, after nebulization of $\mathrm{PGI}_{2}$ or placebo (T3), and 15 (T4) and 25 (T5) minutes after nebulization.

findings also suggest a tendency toward improvement of both RV and LV systolic functions, as well as RV diastolic function. The dose administered was safe, with no systemic hypotension or any effect on platelet aggregation.

Inhaled $\mathrm{PGI}_{2}$ decreases PAP. This has been confirmed in many animal $1^{18-20}$ and human ${ }^{12,21-24}$ studies. Because of this, it reduces RV afterload and can improve RV systolic and diastolic functions. In dogs having PH after hypoxic pulmonary vasoconstriction, Zwissler and colleagues ${ }^{21}$ demon- strated improvement of RV contraction indices through reduction in RV afterload with a small dose of inhaled $\mathrm{PGI}_{2}$. In human subjects one study showed improvement of RV ejection fraction in patients having $\mathrm{PH}$ caused by pulmonary fibrosis. ${ }^{23}$ Haraldsson and colleagues ${ }^{25}$ showed improvement of $\mathrm{RV}$ performance with inhaled $\mathrm{PGI}_{2}$ in patients having $\mathrm{PH}$ after cardiac surgery. Our study demonstrates a reduction in indexed RV stroke work in patients before cardiac surgery. The reduction in RV stroke work index was 
TABLE 3. Arterial and venous blood gas evolution

\begin{tabular}{|c|c|c|c|c|}
\hline & T1 & T2 & T3 & T4 \\
\hline \multicolumn{5}{|l|}{ Epoprostenol } \\
\hline $\mathrm{PaO}_{2}$ & $173.1 \pm 65.2^{*}$ & $428.2 \pm 65.2 \dagger$ & $432.2 \pm 82$ & $431.6 \pm 68.4$ \\
\hline Arterial $\mathrm{pH}$ & $7.41 \pm 0.03$ & $7.44 \pm 0.02$ & $7.46 \pm 0.02$ & $7.45 \pm 0.03$ \\
\hline $\mathrm{PaCO}_{2}$ & $46 \pm 4.2$ & $42 \pm 2.3$ & $39.4 \pm 3.7$ & $41.7 \pm 6$ \\
\hline Bicarbonate & $29.8 \pm 2.8$ & $28.3 \pm 1.6$ & $28.1 \pm 2.1$ & $28.9 \pm 2.5$ \\
\hline $\mathrm{BE}$ & $5.2 \pm 2.4$ & $4.3 \pm 1.6$ & $4.7 \pm 1.7$ & $5.1 \pm 1.8$ \\
\hline $\mathrm{PvO}_{2}$ & $41.9 \pm 6.1$ & $50 \pm 7$ & $46 \pm 4.6$ & $45.6 \pm 5.7$ \\
\hline Venous $\mathrm{pH}$ & $7.39 \pm 0.03$ & $7.39 \pm 0.02$ & $7.42 \pm 0.02$ & $7.41 \pm 0.02$ \\
\hline $\mathrm{PvCO}_{2}$ & $53.1 \pm 3.8$ & $50.5 \pm 3$ & $46.9 \pm 4$ & $49 \pm 5.4$ \\
\hline $\begin{array}{l}\mathrm{PaCO}_{2}-\mathrm{PvCO}_{2} \\
\text { Placebo }\end{array}$ & $6.4 \pm 4.2$ & $8.5 \pm 3.5$ & $7.5 \pm 2.2$ & $7.3 \pm 1.9$ \\
\hline $\mathrm{PaO}_{2}$ & $251.5 \pm 95.4^{*}$ & $443.7 \pm 64.94 \dagger$ & $425.9 \pm 88.75$ & $438.3 \pm 80.62$ \\
\hline Arterial pH & $7.41 \pm 0.02$ & $7.42 \pm 0.02$ & $7.45 \pm 0.03$ & $7.42 \pm 0.05$ \\
\hline $\mathrm{PaCO}_{2}$ & $44.9 \pm 3.3$ & $43.1 \pm 2.8$ & $40.4 \pm 4.6$ & $43 \pm 6.4$ \\
\hline Bicarbonate & $28.7 \pm 1.8$ & $27.8 \pm 1.9$ & $27.8 \pm 2$ & $28.1 \pm 1.6$ \\
\hline BE & $4.2 \pm 1.6$ & $3.6 \pm 1.7$ & $4.1 \pm 1.7$ & $3.9 \pm 1.3$ \\
\hline $\mathrm{PvO}_{2}$ & $44.8 \pm 3.8$ & $55.9 \pm 8$ & $51.9 \pm 6.6$ & $54.1 \pm 9.5$ \\
\hline Venous $\mathrm{pH}$ & $7.39 \pm 0.03$ & $7.39 \pm 0.02$ & $7.40 \pm 0.03$ & $7.40 \pm 0.04$ \\
\hline $\mathrm{PvCO}_{2}$ & $49.6 \pm 4.8$ & $48.6 \pm 3.2$ & $47 \pm 3.9$ & $49.1 \pm 6.4$ \\
\hline $\mathrm{PaCO}_{2}-\mathrm{PvCO}_{2}$ & $4.7 \pm 2.8$ & $5.5 \pm 2.3$ & $6.6 \pm 2.4$ & $6.1 \pm 2.2$ \\
\hline
\end{tabular}

$\mathrm{BE}$, Base excess; $\mathrm{PVO}_{2}$, venous oxygen partial pressure; $\mathrm{PvCO}_{2}$, venous carbon dioxide partial pressure; $\mathrm{PaCO}_{2}-\mathrm{PvCO}_{2}$, arteriovenous difference in carbon dioxide partial pressure.

${ }^{*} P=.05$ between both groups.

$\mathrm{\dagger} P<.001 \mathrm{~T} 1$ to $\mathrm{T} 2$ in both groups.

associated with a tendency to improve RV fractional area change and also RV diastolic function.

Although the decrease in PAP we observed was modest, we observed that its magnitude correlated with the severity of PH. This suggests that the benefit of inhaled $\mathrm{PGI}_{2}$ might be greater with patients with more advanced disease.

There was a statistically significant decrease in heart rate after inhaled $\mathrm{PGI}_{2}$ administration as opposed to that seen after placebo administration, but this was of no clinical significance.

Theoretically, inhaled $\mathrm{PGI}_{2}$ should improve systemic oxygenation by dilating pulmonary vessels in ventilated areas. This has been demonstrated in many models of hypoxia, including adult respiratory distress syndrome. ${ }^{6}$ It has been noted, however, that in patients who are not hypoxemic, as in our population, this effect is not always observed. ${ }^{4,25}$

$\mathrm{PGI}_{2}$ is a powerful inhibitor of platelet aggregation. In vitro, small concentrations of $\mathrm{PGI}_{2}$ can inhibit platelet aggregation. ${ }^{11}$ However, when administered by means of inhalation, this effect has not been shown to occur consistently. ${ }^{6,26,27}$ All previous platelet aggregation studies were done on platelet-rich plasma. We chose to evaluate platelet aggregation on whole blood because the platelet is then surrounded by other blood constituents that might play a role in modulating platelet aggregation. This might be more reflective of the in vivo condition. ${ }^{28}$ We did not show a significant effect on platelet aggregation in our study. This suggests that not enough drug actually reached systemic circulation to have an effect on platelets. This, together with the similar surgical blood losses observed in both groups, suggests that the dose of inhaled $\mathrm{PGI}_{2}$ in the present study is safe.

Two patients died after the operation. One patient in the $\mathrm{PGI}_{2}$ group had mitral valve replacement and a history of prior aortic valve replacement, paroxysmal atrial fibrillation, and sleep apnea. The second patient, from the placebo group, underwent aorta-coronary bypass surgery and had a history of mitral commissurotomy, mitral valve replacement, and chronic obstructive lung disease. They both died of multiple-system organ failure. A $10 \%$ mortality rate was expected in our population. ${ }^{1}$

\section{Study Limitations}

The main limitation of this study is the small sample size that was calculated to observe a $20 \%$ decrease in SPAP. This might not have been sufficient to observe a significant effect on echocardiographic measurements or platelet function.

Only one dose was studied. We did not explore the dose-response curve of inhaled $\mathrm{PGI}_{2}$. The dose used was based on previous experience with the drug in both the operating room and the intensive care unit. When administering drugs by means of nebulization, it is very difficult to determine the effective dose for many reasons. The quantity of drug that actually reaches the lungs is highly variable. It depends on the characteristics of the drug itself, the nebulizer used, the flow of carrier gas to the nebulizer, the 
TABLE 4. TEE examination results

\begin{tabular}{|c|c|c|c|c|c|c|c|c|c|}
\hline & \multicolumn{4}{|c|}{ Left ventricle } & & \multicolumn{4}{|c|}{ Right ventricle } \\
\hline & n & T2 & n & T3 & & n & T2 & n & T3 \\
\hline \multicolumn{10}{|l|}{ Epoprostenol } \\
\hline FAC (\%) & 8 & $0.56 \pm 0.16$ & 8 & $0.63 \pm 0.16$ & FAC $(\%)$ & 7 & $0.47 \pm 0.07$ & 7 & $0.54 \pm 0.08$ \\
\hline LV ESA $\left(\mathrm{cm}^{2}\right)$ & 8 & $10.7 \pm 6.5$ & 8 & $8.5 \pm 5.9$ & RV ESA $\left(\mathrm{cm}^{2}\right)$ & 7 & $7.2 \pm 1.5$ & 7 & $6.2 \pm 2.4$ \\
\hline LV EDA $\left(\mathrm{cm}^{2}\right)$ & 8 & $23.5 \pm 9.7$ & 8 & $20.8 \pm 9.2$ & RV EDA $\left(\mathrm{cm}^{2}\right)$ & 7 & $13.4 \pm 1.8$ & 7 & $13.2 \pm 3.4$ \\
\hline $\mathrm{MEW}(\mathrm{cm} / \mathrm{s})$ & 6 & $138.8 \pm 66.8$ & 6 & $133.7 \pm 46.4$ & $\mathrm{HSW}(\mathrm{cm} / \mathrm{s})$ & 9 & $11.9 \pm 26.7$ & 10 & $14 \pm 17.8$ \\
\hline MEW VTI (cm) & 5 & $34.9 \pm 30.5$ & 5 & $39.3 \pm 40.7$ & HSW VTI (cm) & 9 & $3.4 \pm 6.9$ & 9 & $2.7 \pm 3$ \\
\hline MAW $(\mathrm{cm} / \mathrm{s})$ & 6 & $78.9 \pm 39.7$ & 6 & $72.9 \pm 38.9$ & $\mathrm{HDW}(\mathrm{cm} / \mathrm{s})$ & 9 & $20.7 \pm 11.8$ & 10 & $19.7 \pm 8.7$ \\
\hline MAW VTI $(\mathrm{cm})$ & 5 & $10 \pm 5.6$ & 5 & $8.8 \pm 3.3$ & HDW VTI (cm) & 9 & $5.9 \pm 2.8$ & 9 & $5.4 \pm 2.2$ \\
\hline $\mathrm{PSW}(\mathrm{cm} / \mathrm{s})$ & 9 & $18.6 \pm 55.9$ & 8 & $25.7 \pm 62.3$ & $\mathrm{HAW}(\mathrm{cm} / \mathrm{s})$ & 5 & $17.5 \pm 3.2$ & 5 & $17.7 \pm 6.7$ \\
\hline PSW VTI (cm) & 8 & $7.4 \pm 12.7$ & 8 & $8.4 \pm 13.2$ & HAW VTI (cm) & 5 & $2.1 \pm 0.9$ & 4 & $2.5 \pm 1.6$ \\
\hline $\mathrm{PDW}(\mathrm{cm} / \mathrm{s})$ & 9 & $51.1 \pm 26.2$ & 9 & $50.9 \pm 28.1$ & TEW $(\mathrm{cm} / \mathrm{s})$ & 5 & $55.7 \pm 24.5$ & 3 & $52.3 \pm 17.5$ \\
\hline PDW VTI (cm) & 9 & $12.8 \pm 4.9$ & 9 & $14.6 \pm 6.8$ & TEW VTI (cm) & 4 & $11.3 \pm 3.7$ & 3 & $11.3 \pm 3.8$ \\
\hline $\mathrm{PAW}(\mathrm{cm} / \mathrm{s})$ & 6 & $33.8 \pm 18.9$ & 6 & $37.1 \pm 19.2^{*}$ & $\mathrm{TAW}(\mathrm{cm} / \mathrm{s})$ & 3 & $40.8 \pm 2.9^{\ddagger}$ & 2 & $43.8 \pm 3.8 \ddagger$ \\
\hline PAW VTI (cm) & 6 & $3.4 \pm 1.5$ & 6 & $4.5 \pm 2.4 \dagger$ & TAW VTI (cm) & 2 & $5.3 \pm 1.6$ & 2 & $5.9 \pm 0.3$ \\
\hline \multicolumn{10}{|l|}{ Placebo } \\
\hline FAC $(\%)$ & 10 & $0.54 \pm 0.13$ & 10 & $0.55 \pm 0.05$ & FAC $(\%)$ & 8 & $0.45 \pm 0.08$ & 7 & $0.48 \pm 0.12$ \\
\hline LV ESA $\left(\mathrm{cm}^{2}\right)$ & 10 & $8.48 \pm 5.81$ & 10 & $8.30 \pm 4.18$ & RV ESA $\left(\mathrm{cm}^{2}\right)$ & 8 & $7.56 \pm 3.52$ & 7 & $6.83 \pm 3.77$ \\
\hline LV EDA $\left(\mathrm{cm}^{2}\right)$ & 10 & $17.51 \pm 9.05$ & 10 & $18.35 \pm 9.07$ & RV EDA $\left(\mathrm{cm}^{2}\right)$ & 8 & $13.9 \pm 6.83$ & 7 & $12.44 \pm 4.52$ \\
\hline $\mathrm{MEW}(\mathrm{cm} / \mathrm{s})$ & 8 & $135.5 \pm 34.56$ & 8 & $130.9 \pm 37.04$ & $\mathrm{HSW}(\mathrm{cm} / \mathrm{s})$ & 10 & $16.28 \pm 12.08$ & 10 & $13.7 \pm 8.72$ \\
\hline MEW VTI (cm) & 8 & $29.31 \pm 14.15$ & 8 & $27.51 \pm 21.07$ & HSW VTI (cm) & 9 & $3.96 \pm 3.8$ & 10 & $3.46 \pm 2.84$ \\
\hline $\mathrm{MAW}(\mathrm{cm} / \mathrm{s})$ & 6 & $92.6 \pm 42.66$ & 6 & $84.43 \pm 35.49$ & $\mathrm{HDW}(\mathrm{cm} / \mathrm{s})$ & 10 & $17.33 \pm 5.99$ & 9 & $31.51 \pm 47.42$ \\
\hline MAW VTI (cm) & 6 & $10.67 \pm 6.68$ & 6 & $10.08 \pm 2.32$ & HDW VTI (cm) & 9 & $4.89 \pm 2.2$ & 9 & $4.39 \pm 2.14$ \\
\hline $\mathrm{PSW}(\mathrm{cm} / \mathrm{s})$ & 10 & $39.28 \pm 16.08$ & 10 & $43.22 \pm 24.59$ & $\mathrm{HAW}(\mathrm{cm} / \mathrm{s})$ & 8 & $17.08 \pm 9.82$ & 6 & $12.57 \pm 4.15$ \\
\hline PSW VTI (cm) & 10 & $9.84 \pm 6.13$ & 10 & $10.41 \pm 7.4$ & HAW VTI (cm) & 7 & $2.21 \pm 0.7$ & 6 & $1.99 \pm 0.65$ \\
\hline $\mathrm{PDW}(\mathrm{cm} / \mathrm{s})$ & 10 & $50.06 \pm 12.71$ & 10 & $49.84 \pm 12.07$ & TEW $(\mathrm{cm} / \mathrm{s})$ & 8 & $47.56 \pm 17.26$ & 6 & $48.68 \pm 10.77$ \\
\hline PDW VTI (cm) & 10 & $12.99 \pm 3.51$ & 10 & $12.88 \pm 3.32$ & TEW VTI (cm) & 7 & $9.46 \pm 5.2$ & 6 & $10.4 \pm 2.4$ \\
\hline $\mathrm{PAW}(\mathrm{cm} / \mathrm{s})$ & 8 & $22.76 \pm 7.52$ & 7 & $19.71 \pm 8.8^{*}$ & $\mathrm{TAW}(\mathrm{cm} / \mathrm{s})$ & 7 & $35.44 \pm 11.02$ & 4 & $32.05 \pm 6.8$ \\
\hline PAW VTI (cm) & 8 & $2.31 \pm 1.07$ & 7 & $1.87 \pm 0.9 \dagger$ & TAW VTI (cm) & 6 & $5.3 \pm 1.69$ & 4 & $4.49 \pm 1.07$ \\
\hline
\end{tabular}

FAC, Fractional area change; ESA, end-systolic area; EDA, end-diastolic area; $M E W$, mitral E wave; MAW, mitral A wave; PSW, pulmonary S wave; PDW, pulmonary D wave; PAW, pulmonary A wave flow; HSW, hepatic $S$ wave; HDW, hepatic D wave; HAW, hepatic A wave; TEW, tricuspid E wave; TAW, tricuspid A wave; $V T I$, velocity time interval; $L V$, left ventricular; $R V$, right ventricular.

${ }^{*} P=.05$ at $\mathrm{T} 3$ between both groups.

$\dagger P=.02$ at $\mathrm{T} 3$ between both groups

$\ddagger P<.01 \mathrm{~T} 2$ to $\mathrm{T} 3$ in epoprostenol group.

density of the carrier gas, the amount of drug remaining in the nebulizer, and the humidity and temperature in the nebulizer circuit. ${ }^{29,30}$ Particles of 1 to $5 \mu \mathrm{m}$ are considered to be in the respirable range. ${ }^{29} \mathrm{We}$ used high nebulizer flows because this increases the proportion of particles produced in the respirable range, and during mechanical ventilation, it is known that less than $10 \%$ of the medication actually reaches the alveolar epithelium. The $60-\mu \mathrm{g}$ dose we nebulized over 10 minutes is approximately equal to $85 \mathrm{ng} \times$ $\mathrm{kg}^{-1} \times \mathrm{min}^{-1}$.

$\mathrm{PGI}_{2}$ might be an alternative to iNO. Both can induce selective pulmonary vasodilatation. The effect of iNO remains localized through inactivation by hemoglobin as soon as it reaches the circulation. However, disadvantages related to the use of iNO have been identified, such as the production of toxic metabolites and methemoglobinemia when given at high concentrations for a long period of time. It requires costly and specialized equipment. Epoprostenol, on the other hand, has no known toxic metabolites and very few side effects. It can be administered by means of simple nebulization with minimal equipment, which is an advantage for use in the operating room. A full 24 hours of treatment is estimated to cost approximately $\$ 115.00$ CAN (approximately $\$ 70.00 \mathrm{US}$ ).

\section{Conclusion}

Inhaled $\mathrm{PGI}_{2}$ reduces $\mathrm{PAP}$ in the preoperative period. By doing so, improvements in RV function through a decrease in indexed RV stroke work can be achieved. It is a safe medication that does not increase platelet dysfunction or perioperative bleeding. This exploratory trial confirms that inhaled $\mathrm{PGI}_{2}$ can be safely studied in the postbypass period, where treatment for unexpected $\mathrm{PH}$ can be encountered. 
TABLE 5. Whole blood platelet aggregation impedance and luminescence results

\begin{tabular}{lcc}
\hline & T2 & T3 \\
\hline Epoprostenol & & \\
ADP imp $(\Omega)$ & $16.67 \pm 6.74$ & $14.9 \pm 6.38$ \\
ADP lum (nm) & $0.69 \pm 0.23$ & $0.63 \pm 0.2$ \\
Collagen imp ( $\Omega$ ) & $36.44 \pm 6.8$ & $36.1 \pm 5.68$ \\
Collagen lum (nm) & $0.75 \pm 0.26^{*}$ & $0.71 \pm 0.26 \dagger$ \\
AA imp ( $\Omega$ ) & $9.78 \pm 8.69$ & $6.8 \pm 7.79$ \\
AA lum (nm) & $0.81 \pm 0.47 \ddagger$ & $0.72 \pm 0.41$ \\
Platelet count & $126.3 \pm 32.64$ & $126.8 \pm 36.32 \S$ \\
Blood loss & & \\
Intraoperative & $685.5 \pm 350.9$ & \\
Postoperative & $725.5 \pm 676.3$ & \\
Placebo & & \\
ADP imp ( $\Omega$ ) & $19.7 \pm 6.4$ & $17.3 \pm 7.72$ \\
ADP lum (nm) & $0.82 \pm 0.33$ & $0.85 \pm 0.33$ \\
Collagen imp $(\Omega)$ & $33 \pm 3.89$ & $35.9 \pm 6.08$ \\
Collagen lum (nm) & $1.17 \pm 0.55^{*} \ddagger$ & $1.1 \pm 0.52 \dagger \ddagger$ \\
AA imp ( $\Omega$ ) & $13.4 \pm 9.99$ & $13.3 \pm 9.4$ \\
AA lum (nm) & $1.38 \pm 0.76^{*} \S$ & $1.1 \pm 0.6 \S$ \\
Platelet count & $160.9 \pm 40.19$ & $164 \pm 40.25 \dagger$ \\
Blood loss & & \\
Intraoperative & $660 \pm 504.3$ & \\
Postoperative & $664 \pm 352$ & \\
\hline ADP Adenosine & &
\end{tabular}

$\overline{A D P}$, Adenosine diphosphate; imp, impedance; lum, luminescence; $A A$, arachidonic acid.

${ }^{*} P<.05$ between both groups at $\mathrm{T} 2$.

$\mathrm{\dagger} P=.055$ between both groups at $\mathrm{T} 3$.

$\ddagger P<.05 \mathrm{~T} 2$ to $\mathrm{T} 3$ in placebo group.

$\S P<0.01$ T2 to T3 in placebo group.

\section{References}

1. Bernstein AD, Parsonnet V. Bedside estimation of risk as an aid for decision-making in cardiac surgery. Ann Thorac Surg. 2000;69:823-8.

2. Radermacher P, Santak B, Wust HJ, Tarnow J, Falke KJ. Prostacyclin for the treatment of pulmonary hypertension in the adult respiratory distress syndrome: effects on pulmonary capillary pressure and ventilation-perfusion distributions. Anesthesiology. 1990;72:238-44.

3. Goldman AP, Delius RE, Deanfield JE, Macrae DJ. Nitric oxide is superior to prostacyclin for pulmonary hypertension after cardiac operations. Ann Thorac Surg. 1995;60:300-5.

4. Haraldsson A, Kieler-Jensen N, Nathorst-Westfelt U, Bergh CH, Ricksten SE. Comparison of inhaled nitric oxide and inhaled aerosolized prostacyclin in the evaluation of heart transplant candidates with elevated pulmonary vascular resistance. Chest. 1998;114:780-6.

5. Zwissler B, Kemming G, Habler O, et al. Inhaled prostacyclin ( $\left.\mathrm{PGI}_{2}\right)$ versus inhaled nitric oxide in adult respiratory distress syndrome. Am J Respir Crit Care Med. 1996;154:1671-7.

6. van Heerden PV, Barden A, Michalopoulos N, Bulsara MK, Roberts BL. Dose-response to inhaled aerosolized prostacyclin for hypoxemia due to ARDS. Chest. 2000;117:819-27.

7. Olschewski H, Walmrath D, Schermuly R, Ghofrani A, Grimminger F, Seeger W. Aerosolized prostacyclin and iloprost in severe pulmonary hypertension. Ann Intern Med. 1996;124:820-4.

8. Walmrath D, Schneider T, Pilch J, Grimminger F, Seeger W. Aerosolised prostacyclin in adult respiratory distress syndrome. Lancet. 1993;342:961-2.

9. Montalescot G, Drobinski G, Meurin P, et al. Effects of prostacyclin on the pulmonary vascular tone and cardiac contractility of patients with pulmonary hypertension secondary to end-stage heart failure. Am J Cardiol. 1998;82:749-55.
10. Rich S, McLaughlin VV. The effects of chronic prostacyclin therapy on cardiac output and symptoms in primary pulmonary hypertension. J Am Coll Cardiol. 1999;34:1184-7.

11. van Heerden PV, Gibbs NM, Michalopoulos N. Effect of low concentrations of prostacyclin on platelet function in vitro. Anaesth Intensive Care. 1997;25:343-6.

12. Hache $\mathrm{M}$, Denault AY, Belisle $\mathrm{S}$, et al. Inhaled prostacyclin $\left(\mathrm{PGI}_{2}\right)$ is an effective addition to the treatment of pulmonary hypertension and hypoxia in the operating room and intensive care unit [L'inhalation de prostacycline $\left(\mathrm{PGI}_{2}\right)$ est un traitement complémentaire efficace de l'hypertension pulmonaire et de l'hypoxie observées en salle d'opération et à l'unité des soins intensifs]. Can J Anaesth. 2001;48: 924-9.

13. Moraes D, Loscalzo J. Pulmonary hypertension: newer concepts in diagnosis and management. Clin Cardiol. 1997;20:676-82.

14. Fyrenius A, Wigstrom L, Bolger AF, et al. Pitfalls in Doppler evaluation of diastolic function: insights from 3-dimensional magnetic resonance imaging. J Am Soc Echocardiogr. 1999;12:817-26.

15. Schnittger I, Fitzgerald PJ, Daughters GT, et al. Limitations of comparing left ventricular volumes by two dimensional echocardiography, myocardial markers and cineangiography. Am J Cardiol. 1982;50: 512-9.

16. Bernard F, Denault A, Babin D, et al. Diastolic dysfunction is predictive of difficult weaning from cardiopulmonary bypass. Anesth Analg. 2001;92:291-8.

17. Couture P, Denault AY, Carignan S, Boudreault D, Babin D, Ruel M. Intraoperative detection of segmental wall motion abnormalities with transesophageal echocardiography. Can J Anaesth. 1999;46:827-31.

18. Welte M, Zwissler B, Habazettl $\mathrm{H}$, Messmer $\mathrm{K}$. $\mathrm{PGI}_{2}$ aerosol versus nitric oxide for selective pulmonary vasodilation in hypoxic pulmonary vasoconstriction. Eur Surg Res. 1993;25:329-40.

19. Zobel G, Dacar D, Rodl S, Friehs I. Inhaled nitric oxide versus inhaled prostacyclin and intravenous versus inhaled prostacyclin in acute respiratory failure with pulmonary hypertension in piglets. Pediatr Res. 1995;38:198-204.

20. Max M, Kuhlen R, Dembinski R, Rossaint R. Effect of aerosolized prostacyclin and inhaled nitric oxide on experimental hypoxic pulmonary hypertension. Intensive Care Med. 1999;25:1147-54.

21. Zwissler B, Welte M, Messmer K. Effects of inhaled prostacyclin as compared with inhaled nitric oxide on right ventricular performance in hypoxic pulmonary vasoconstriction. J Cardiothorac Vasc Anesth. 1995;9:283-9.

22. Bein T, Metz C, Keyl C, Sendtner E, Pfeifer M. Cardiovascular and pulmonary effects of aerosolized prostacyclin administration in severe respiratory failure using a ventilator nebulization system. $J$ Cardiovasc Pharmacol. 1996;27:583-6.

23. Olschewski H, Ghofrani HA, Walmrath D, et al. Inhaled prostacyclin and iloprost in severe pulmonary hypertension secondary to lung fibrosis. Am J Respir Crit Care Med. 1999;160:600-7.

24. Mikhail G, Gibbs J, Richardson M, et al. An evaluation of nebulized prostacyclin in patients with primary and secondary pulmonary hypertension. Eur Heart J. 1997;18:1499-504.

25. Haraldsson A, Kieler-Jensen N, Ricksten SE. Inhaled prostacyclin for treatment of pulmonary hypertension after cardiac surgery or heart transplantation: a pharmacodynamic study. $J$ Cardiothorac Vasc Anesth. 1996;10:864-8.

26. Burghuber OC, Silberbauer K, Haber P, Sinzinger H, Elliott M, Leithner C. Pulmonary and antiaggregatory effects of prostacyclin after inhalation and intravenous infusion. Respiration. 1984;45:450-4.

27. Haraldsson A, Kieler-Jensen N, Wadenvik H, Ricksten SE. Inhaled prostacyclin and platelet function after cardiac surgery and cardiopulmonary bypass. Intensive Care Med. 2000;26:188-94.

28. Sharp DS, Beswick AD, O’Brien JR, Renaud S, Yarnell JW, Elwood PC. The association of platelet and red cell count with platelet impedance changes in whole blood and light-scattering changes in platelet rich plasma: evidence from the Caerphilly Collaborative Heart Disease Study. Thromb Haemost. 1990;64:211-5.

29. Coates AL, Ho SL. Drug administration by jet nebulization. Pediatr Pulmonol. 1998;26:412-23.

30. Fink JB. Aerosol device selection: evidence to practice [in process citation]. Respir Care. 2000;45:874-85. 